\title{
Ergologia e psicossociologia do trabalho: desconforto intelectual, interseções conceituais e trabalho em comum*
}

\author{
Daisy Moreira Cunha ${ }^{1}$ \\ Universidade Federal de Minas Gerais (Belo Horizonte, MG)
}

\begin{abstract}
O presente artigo apresenta as origens, alguns conceitos e aspectos metodológicos da ergologia e da psicossociologia do trabalho, demonstrando zonas de interseção férteis para uma possível colaboração entre essas duas abordagens teórico-metodológicas. Ambas as perspectivas teóricas adotam a postura epistemológica subjacente, segundo a qual não é possível construir conhecimentos sobre trabalho sem que os protagonistas colaborem em dispositivos e abordagens metodológicas especialmente elaboradas para esse fim e apostem numa perspectiva interdisciplinar, multidisciplinar e transdisciplinar na produção de saberes. No final do artigo, é apresentada uma pesquisa sobre o trabalho de domésticas diaristas no Brasil, que funciona como terreno de convergência e confrontação conceitual e metodológica entre as duas abordagens do trabalho em foco.
\end{abstract}

Palavras-chave: Ergologia, Psicossociologia do trabalho, Desconforto intelectual.

L'ergologie et la psychosociologie du travail: inconfort intellectuel, intersections conceptuelles et travail en commun

L'article présente les origines, les principaux concepts, la méthode et les méthodologies de l'ergologie et de la psychosociologie du travail. Par des cheminements différents, les deux perspectives théoriques et méthodologiques montrent des zones d'intersection fertiles pour un possible travail en commun: (a) la posture épistémologique sous jacente selon laquelle il n'est pas possible de construire des connaissances sur le travail, sans que les protagonistes du travail y collaborent dans des dispositifs et des approches méthodologiques spécialement élaborées à cette fin et; (b) par une approche multidisciplinaire, interdisciplinaire et transdisciplinaire. Une étude sur le travail des femmes de ménage, payées à la journée, est présentée comme terrain de convergence et de confrontation conceptuelles et méthodologiques, entre ces deux approches.

Mots-clés: Ergologie, Psychosociologie du travail, Inconfort intellectuel.

The difficult but fruitful bridges between ergology and work sociopsychology

This paper discusses the origins, main concepts, and methodologies in the Ergology and in the Work Sociopsychology. Although being different perspectives, both theoretical and methodological approaches have areas of intersection, among them: (a) epistemological concept according to which it is not possible to build knowledge without the protagonists of the work, and their collaboration on the apparatus and methodological approaches especially prepared for this purpose; and (b) multi-inter and transdisciplinary approaches. This research presents a case study on Brazilian house servants which points out a methodological and conceptual convergence field.

Keywords: Ergology, Work Sociopsychology, Intellectual unconfort.

\section{O desconforto intelectual como ponto de partida}

A ergologia nasce buscando compreender os meandros do trabalho industrial e dos serviços nas grandes cidades. A psicossociologia do trabalho tem em seu campo de pesquisa/intervenção trabalhadores do mercado informal, de ofícios marginais e com pouco prestígio social - campos denominados dirty work (Chapoulie, 1984; Hughes, 2010; Lhuilier, 2005). Esse movimento em direção aos trabalhadores nas franjas do mercado de trabalho denota um desconforto e funda uma busca por outros sentidos na experiência laboral para além

\footnotetext{
* Publicado originalmente em: Nouvelle Revue de Psychosociologie, 15 (1), 77-90, 2013. DOI: 10.3917/nrp.015.0077

1 Doutora em Filosofia pela Universidade de Provence (França). Coordenadora do PPGE Conhecimento e Inclusão Social da Universidade Federal de Minas Gerais (Brasil).
} 
daqueles comumente revelados pelos estudos hegemônicos neste campo. Há que se encontrar vida onde parece não haver no trabalho, espaços para compreender que o homem se forja interagindo com as situações, as injunções e as conjunturas que vivenciou. Nesse processo, ambos os approches buscam desvelar o "imaginário radical instituinte" (Castoriadis, 1990, citado por Machado, 2010, p. 179) como capacidade humana de engendrar novas formas de vida social, de fazer história, mesmo em condições adversas - ou seja, de não se enclausurar em formas heterônomas já instituídas.

Portanto, a emancipação do homem como sujeito na relação com o meio exige de ambas as perspectivas teóricas mais sensibilidade para abarcar sem preconceitos toda a complexidade dessa relação. Também é necessário que, de forma exigente, compreenda-se que em cada situação existem escolhas sendo feitas em função de valores e saberes dos quais o homem é portador.

Para as perspectivas da ergologia e da psicossociologia, o inter, o multi e o transdisciplinar são caminhos possíveis para que se compreenda a complexidade das atividades humanas em situações de trabalho. Lhuilier (citada por Carreteiro \& Barros, 2011, p. 214 e p. 222) chama a atenção para o vasto interesse da psicossociologia no que se refere ao "vínculo social e às suas declinações (do intersubjetivo ao societal), quer sob a forma de conflito, de dominação, de exclusão ou de solidariedade cooperativa, de aliança e de trocas". A autora também ressalta avanços ocorridos durante as incorporações do "campo pulsional" e do "registro do libidinal" à compreensão das situações sociais analisadas.

A psicossociologia investiu muito na compreensão do sujeito em diversos enquadramentos da vida cotidiana, tais como agrupamentos diversos, organizações e instituições das quais participa. Assim, compreende-se a importância, para a psicossociologia, das histórias de vida como um caminho para encontrar um "sujeito" mais inteiro, pleno de sentidos no manejo cotidiano do trabalho e da vida. ${ }^{2}$

Já a ergologia, inspirada pelas Comunidades Científicas Ampliadas (Oddone, 1981), tem na ergonomia da atividade uma propedêutica (Schwartz, 1987). De ambas as abordagens clínicas do trabalho, herda-se a hipótese da existência de uma atividade que faz a experiência operária dos modos de produção, cujo desvelamento somente é possível no diálogo entre pesquisadores e trabalhadores. Os percursos metodológicos na ergologia sempre buscaram dimensionar esse "ser inteiro" através da noção de "corpo-si" - homem, ser singular, vivo e sociocultural - nas situações de trabalho.

Ambas as perspectivas teórico-metodológicas buscam construir leituras antropológicas do trabalho colocando na cena das situações laborais sujeitos vivos, encarnados, fazendo uso de si por outrem, mas também por si mesmos. No encontro com esse "sujeito inteiro", tais abordagens elucidam múltiplas facetas da experiência de trabalho (prazer, dor, sofrimento, saúde), bem como as decorrentes indagações sobre o exercício profissional. Nesse diálogo interperspectivas, surgem novos aportes para pensar as articulações do trabalho com a vida, com a formação de identidades, de competências profissionais, com os meandros do ser nos ofícios laborais. O desafio é comum: integrar um olhar mais plural sobre a experiência dos trabalhadores em nossas análises, entendendo a complexidade dessa experiência; compreender saberes e valores operantes nas situações de trabalho, tendo em vista sua transformação. Tanto a ergologia quanto a psicossociologia do trabalho, na condição de clínicas, visam ao favorecimento da melhoria das condições de trabalho dos indivíduos por meio da ampliação do seu poder de agir.

Compreende-se, portanto, a interposição do trabalho conceitual na confrontação entre a categorização utilizada pelos próprios trabalhadores e aquelas utilizadas pelos pesquisadores e seus referenciais teórico-metodológicos. E é em Hugues (2010) que encontramos pistas do

2 Cf., por exemplo, Carreteiro e Barros (2011). 
quanto os desconfortos comuns geraram também um ponto de interseção sobre o que deve ser todo trabalho conceitual:

Aqueles que se esforçam, particularmente, para erradicar nas pessoas honestas, enquanto indivíduos, todos os sentimentos que parecem levar ao trabalho sujo deste mundo, seja ele pequeno ou grande, pensarão talvez que minhas observações se dirigem a seus métodos. Eles têm razão, em certa medida; eu insisto que consagremos parte de nossos esforços aos mecanismos sociais em jogo, assim como ao indivíduo e aos seus sentimentos, em relação àqueles que são diferentes dele. (Hughes, 2010, p. 34)

O trabalho é um contexto de vida no qual a natureza das ressonâncias entre o psíquico e o social pode ser problematizada, não sendo, porém, o único elemento em torno do qual se organiza o drama humano (Amado, 1994; Amado \& Enriquez, 2011). O trabalho seria uma experiência na qual o homem pode ser compreendido num duplo ordenamento entre elementos intrapsíquicos singulares - considerando-se, inclusive, o campo pulsional - e elementos do universo social no qual se encontra. Portanto, não há uma afirmação a priori e abstrata da centralidade do trabalho na vida social; há, sim, um resgate dessa experiência como um território vasto de experimentação humana nas coletividades em que os homens se inserem. $\mathrm{E}$, se as duas abordagens não trilham os mesmos caminhos teórico-metodológicos para compreender o trabalho enquanto experiência, encontram-se no território das situações de trabalho real, com approches muito próximos, estabelecendo trocas dialógicas entre si por meio de demandas de reflexão e intervenção interpostas pela experiência de trabalho.

\section{A clínica como método, os obstáculos epistemológicos e a usinagem dos conceitos}

Desde a fundação do dispositivo Análise Pluridisciplinar sobre Situações de Trabalho (APST), em 1987, Yves Schwartz interroga o trabalho como a experiência que os homens fazem das forças produtivas de seu tempo - é uma experiência sem fronteiras definidas, não se sabendo ao certo quando emerge na história humana. $O$ autor sintetiza esse desafio em Reconnaissances du travail - pour une approche ergologique:

Falar do trabalho é se expor a todo tipo de encontros frequentemente inesperados, onde podemos crer na perda do fio de sua preocupação inicial: é, por exemplo, ser conduzido a se perguntar como se articulam o corpo, o psiquismo e as normas, como se articulam o privado e o público, o cálculo mercantil e os valores que não têm escalas de medida, o industrioso, o ético e o político; é encontrar processos dinâmicos onde emergem o linguístico na atividade e questionam novamente as teorias da linguagem, as relações do microscópico e do macroscópico, do local e do global... A interrogação sobre a maneira de onde vêm as configurações novas da atividade e da vida, quer dizer, das histórias e da história, nos atinge sub-repticiamente em todos os cruzamentos... (Schwartz, 1987, p. 2).

Compreendido assim, o trabalho - experiência-síntese de múltiplas determinações - é processo e se abre para questões éticas, epistemológicas e políticas. E, mobilizando dimensões plurais do ser humano, é, portanto, um ponto de retorno sem precedentes. É necessário reinterrogar os saberes produzidos sobre trabalho, mas, também, produzidos no trabalho. $\mathrm{O}$ trabalho é a experiência-síntese pela qual o homem manifesta sua humanidade (ser biológico, histórico e sociocultural).

O surgimento do dispositivo APST deixa entrever um mal-estar ante o instrumental conceitual disponível para analisar as transformações em curso, bem como diante da experiência de trabalho vislumbrada como um processo de transformação contínua. Anos mais 
tarde, quando da criação do Departamento de Ergologia na Universidade de Provence, a questão reaparece:

[...] o instrumental conceitual parece precioso, inicia posturas de pensamento e, simultaneamente, a realidade o toma sempre em falta, em flagrante delito de generalização abusiva. Ele não pode ser o passaporte enquadrador da inteligibilidade das mudanças reais. Ele auxilia a penetrar nestas, mas é um pouco como se a realidade não cessasse de recomplicar isto que ele acreditaria ter prendido em suas redes (Schwartz, 1987, p. 8).

Encontramos nessa obra o anúncio programático do que deva ser o trabalho de "usinagem dos conceitos" - este deve exigir do pesquisador um mergulho nas situações concretas, revelando nelas os valores e os saberes aí operantes em dimensões singularizantes, apontando o que está em jogo e o que perpassa as transformações nas situações analisadas. Deve, ainda, possibilitar que se articulem dinâmicas locais, específicas e singulares com os planos mais gerais do conjunto econômico-social.

Desde essa época, algumas exigências éticas e epistemológicas conformariam a abordagem ergológica da experiência que faz a atividade de trabalho desde então. Trata-se, ressaltemos, de uma abordagem; não é uma disciplina em sentido stricto. Exige que se cultive uma disciplina ergológica no sentido lato, como uma norma na investigação, para dar visibilidade, permanentemente, aos processos ergológicos compreendidos como momento singular de um debate indefinidamente renovado entre normas antecedentes e tentativas de renormalização. A substância desse debate tem uma aderência local ineliminável e requer, portanto, que se faça história, sem que possamos jamais exibir "condições aos limites" (Schwartz, 1987, p. 23) deste centro de vida que se procura renormalizar. Evidentemente, não se dispensam as disciplinas epistêmicas no trato dos fatos humanos, mas é necessário considerálas em cruzamento permanente, pois todo processo ergológico exige rigor conceitual nos diversos níveis de saberes, rigor que não pode ser definido apenas no plano epistêmico dos protocolos disciplinares.

Devem ser colocadas em sinergia a disciplina ergológica e as disciplinas epistêmicas, visando retrabalhar os respectivos patrimônios; na tradição mais genuína da epistemologia histórica francesa, principalmente nas contribuições de Georges Canguilhem, todo pensar ergológico exige mergulho na história. Assim, há que se cultivar uma postura ética e política para que não sejam tratados dogmaticamente valores em processamento nas atividades em que os homens fazem "usos de si por si e por outrem".

Analisar o trabalho como experiência do ponto de vista da atividade, tal como nos propomos nas abordagens clínicas, não é algo evidente, é um permanente desafio epistemológico, político e ético. Reconhecer que os trabalhadores fazem experiência nos meandros do processo produtivo, nas situações de trabalho nas quais se encontram, evidencia o problema teórico-metodológico que envolve o modo de aproximar tais experiências, ou como analisar a atividade. Será preciso trazer os protagonistas, em sua diversidade, para uma colaboração efetiva na construção de conhecimento sobre trabalho.

Quantos de nós não estivemos diante dos dilemas do "recortar para conhecer" nas encruzilhadas do "intervir ou pesquisar"? Nessa passagem entre problemas da experiência e problemas de pesquisa, muitas demandas sociais, permeadas de obstáculos epistemológicos, se perdem em função das opções feitas pelo pesquisador. Mas, para além de quem define as demandas de pesquisa/intervenção, em relação ao problema a ser analisado, é necessário que se questione: como "recortar" essa experiência de trabalho, tendo em vista sua complexidade?

Nessa perspectiva aberta à reflexão sobre o que seja trabalho, cabe muito mais uma ideia de abordagem do que propriamente a ideia de uma "escola" teórico-metodológica. De acordo com Schwartz (2000), é démarche, caminho, método pensado num sentido amplo, mas que, paradoxalmente, impõe rigor conceitual para aproximar atividade humana como 
"enigma". É nessa perspectiva que a abordagem ergológica do trabalho mescla inextricavelmente no trabalho do pesquisador - e em todas as áreas de conhecimento - o epistemológico e o axiológico nas situações de trabalho e da vida e, portanto, em todas as atividades de trabalho analisadas. $\mathrm{O}$ uso dos conceitos traz conseqüências no desvelamento das "dramáticas dos usos do corpo-si por ele mesmo e por outrem" no trabalho vislumbrado como processo ergológico. O próprio uso do termo "ergológico" deve ser observado como apropriado, porque é o termo mais geral, mais neutro, extensivo e indeterminado para evocar os processos interativos que colocam o homem e o meio em uma relação.

Schwartz (2000) chama a atenção para o fato de que os conceitos do tipo ergológico devem ser forjados de modo adequado para que se possa confrontar urgências e demandas do presente, no aqui e no agora dos atos situados de trabalho, sem que seja vedada a porosidade necessária entre o local e o global, o universal e o particular, o privado e o público, a vida em geral e a vida no trabalho.

A pergunta fundadora do APST, “como pensar as mudanças 'do trabalho' sem se encontrar imediatamente confrontado à interrogação sobre a existência do objeto supostamente perene através de suas modificações?" (Schwartz, 1987, p. 4), foi fundamental para pavimentar um novo regime de produção de saberes sobre trabalho. Se defino o método tendo em vista uma hipótese que representa um objeto de investigação, minha compreensão do que seja trabalho define, em última instância, como faço para conhecê-lo. Será preciso forjar lugares em que a experiência das mudanças no trabalho fertilize a construção de conhecimento, e vice-versa, através de trocas permanentes. Mais que isso, Schwartz nos lembra também do princípio de considerar como objeto de reflexão o "ato, no fundo eminentemente problemático, de conceituar a atividade dos outros" (Schwartz, 1987, p. 8). Assim, ficamos constrangidos a transformar as experiências de trabalho relatadas pelos trabalhadores (expressando demandas da atividade de trabalho) e a nossa própria experiência nesses dispositivos em questões teóricas e/ou objetos de intervenção.

Os "dispositivos dinâmicos a três polos" são, por excelência, lugares nos quais pesquisadores de diversas áreas do conhecimento e trabalhadores de diversos setores colaboram para construir um novo regime de produção de saberes sobre trabalho. Tais dispositivos recuperam a complexa relação teoria-prática na tensão permanente entre saberes-atividadesvalores - nas palavras de Schwartz (2000), a dupla antecipação entre o conceito e a experiência em permanência estruturando as configurações históricas. Eles alimentam competências diversas no pesquisador e nos trabalhadores participantes: permitem um trabalho de enraizamento das várias profissionalidades nas complexidades da atividade, ao mesmo tempo que permitem validação dos saberes, remodelamento de alguns deles e, principalmente, possibilitam que haja menos erros relacionados a mutilações conceituais.

Nesses quase trinta anos de elaboração e de experimentações de dispositivos onde se encontram pesquisadores e trabalhadores de várias áreas, a ideia do trabalho como atividade ganha amplitude e profundidade nos embates entre o conceito e a experiência. Todo exercício do trabalho implica a "atividade industriosa" humana em suas dramáticas no debate entre normas antecedentes e renormalizações, mobilizando aí saberes/valores de todos os tipos, sendo que, para ser compreendido, o conteúdo desse debate de normas sempre deverá ser contextualizado - situado no espaço e no tempo. A "atividade industriosa" debate normas e promove renormalizações, sendo continuidade/ruptura em permanência por todos os lados, desdobrando-se em novas formas de viver, fazendo emergir relações de tipo novo, criando e ampliando possibilidades segundo exigências humanas vitais. $O$ trabalho passa a ser compreendido como evidência viva, mas que escapa a definições.

E, se, por isso mesmo, não podemos viver sem uma permanente dialética entre os saberes das disciplinas epistêmicas e das ergológicas, como é possível recortar objetos de 
pesquisa sobre trabalho nos vários domínios disciplinares? Como delimitar objetos de pesquisa, na tentativa de

[...] compreender estas formas tão diferentes nas quais está em jogo a história humana, sem portanto perder o contato com isto que é sem dúvida o princípio mesmo de explicação da existência de uma história perpetuamente renovada? Somos capazes de construir a "refração" desta estrutura no seio das construções teóricas próprias para cada domínio e forma cultural se incorporando em sistemas incrustados ou contíguos, esta atividade humana? Somos capazes de construir um conceito, permitindo auxiliar em intervenções sobre a situação, sem anular as brasas que aí cobrem ou sem se colocar em situação daquele que sabe de antemão isto que ele é e que sabe o que é preciso fazer? (Schwartz, 2000, p. 680).

O conceito de "uso de si" foi cunhado obedecendo a princípios de não mutilação das atividades de trabalho: (a) instala um ponto de refração entre objetivo/subjetivo, dando potente "chave de análise" das situações observadas; (b) permite analisar diversos usos em múltiplas dimensões, e, nisso, tais usos implicam as diversas disciplinas epistêmicas para se fazer compreender, ainda que determinados saberes possam anular a dialética necessária entre as duas dimensões da refração entre subjetivo/objetivo; (c) exige vislumbrar sempre resíduos que não se deixam generalizar, ou seja, as variações e as singularidades do caso analisado. Esses usos indicam dramáticas negociações entre os usos de si por si e por outrem, "[...] sendo que a substância, o conteúdo, e as circunstâncias dessas dramáticas, a maneira como elas tecem os elementos heterogêneos, não são mais que parcialmente antecipáveis e objetiváveis, elas 'fazem história' mais ou menos localmente ou globalmente" (Schwartz, 1987, p. 7).

A abordagem ergológica do trabalho, na condição de clínica ampliada, se interessa por incorporar, por meio da ideia de "atividade industriosa" deste "corpo-si", as renormalizações do "sujeito" - produto das dramáticas desse "uso de si" -, implementadas no lastro sociocultural, econômico e histórico. É preciso revelar o conteúdo desses dramas vividos no singular para além do sofrimento, os meandros da produção da saúde, que revelam a criatividade dos trabalhadores na construção de reservas de alternativas presentes nas configurações históricas nas quais se inserem.

\section{Usos de si no "escuro território do íntimo alheio"}

Em tese de doutoramento orientada por nós, Ribeiro (2011) investiga "dramáticas do uso do corpo-si" no emprego doméstico. Observa como os empregados criam novas normas para dar sentido e gerir as atividades cotidianas nos espaços domésticos nos quais se inserem, diante das normas definidas pelos empregadores, dos marcos regulatórios e dos padrões socioculturais dos usos nesse segmento do mercado de trabalho.

Inicialmente, buscamos dimensionar o trabalho de empregadas domésticas no mercado de trabalho informal brasileiro, apresentando características sociodemográficas dessa população ativa. Esse segmento do mercado compreende diversos trabalhos, como os de cozinheira, passadeira, governanta, babá e faxineira. No Brasil, em 2010, o contingente de trabalhadores domésticos remunerados somava 7.223 .000 pessoas, das quais $93 \%$ eram mulheres, conforme a Pesquisa Nacional por Amostra de Domicílios (PNAD) do Instituto Brasileiro de Geografia e Estatística (IBGE). Esse é o segmento que garante a inserção ocupacional de 17\% das mulheres que trabalham.

Algumas das "condições do uso de si por outrem" podem ser estatisticamente mensuráveis ao se desvelarem atributos pessoais (idade, sexo, posição no domicílio e na família, cor, migração, tempo de residência na região e escolaridade) da população economicamente ativa nesse segmento da economia. Esses indicadores econômicos, produzidos com estudos 
documentais e de tipo qualitativo, captam normas socioculturais dos usos feitos dessa população ativa no mercado informal brasileiro. Nesse trabalho, que é objeto de preconceitos, estigmas e discriminações na sociedade brasileira, emprega-se "força de trabalho" preponderantemente feminina: mulheres com meia-idade, negras e com pouca escolaridade. As "condições dos usos" nesse mercado remontam à escravatura, com características que persistem até os dias atuais, ancoradas nas habilidades do cuidado consideradas historicamente como pertencentes ao gênero feminino. Assim, reforça-se, segundo Hirata (citada por Mariuzzo, 2006, p. 3), a ideia de "guetos femininos" no mercado de trabalho. Delegamos a elas o "trabalho sujo": limpeza da sujeira, a arrumação da desordem, dentre outras tarefas consideradas menos nobres no cotidiano doméstico de nossa existência, para utilizar expressão cunhada por Hughes (2010, p. 21).

Os marcos regulatórios do emprego doméstico no Brasil mostram-se frágeis e bastante genéricos para enquadrar os usos dessa força de trabalho num mercado que resiste à formalização do emprego. O Decreto no 92.180, de 19 de dezembro de 1985, instituiu o valetransporte e o garantiu também para os trabalhadores domésticos. A Lei no 10.208 , aprovada em 23 de março de 2001, facultou o acesso do empregado doméstico ao Fundo de Garantia por Tempo de Serviço (FGTS) e ao seguro-desemprego. Porém, tendo sido esses direitos definidos como opcionais, apenas uma pequena parcela de empregadores inscreveu o trabalhador doméstico no FGTS, restringindo a poucos o acesso ao seguro-desemprego.

A Lei $\mathrm{n}^{\mathrm{O}}$ 11.324, de 19 de julho de 2006, buscou incentivar a formalização dos contratos de trabalho doméstico autorizando a dedução, no Imposto de Renda de pessoas físicas, das despesas com o pagamento da contribuição do empregador ao INSS. Também estendeu os direitos trabalhistas das domésticas, que passaram a incorporar também férias de trinta dias, estabilidade para a gestante, direito aos feriados civis e religiosos e proibição de descontos como forma de pagamento por moradia, alimentação e uso de produtos de higiene pessoal no local de trabalho.

A conquista desses direitos trabalhistas aponta para o rompimento de uma situação de corveia muito característica do emprego no setor. Porém, quando associada aos valores salariais praticados no mercado para empregadas domésticas, influencia a opção crescente de empregadas e patroas pelo trabalho de diaristas, que escapa a qualquer regulamentação, pois até recentemente essas profissionais não possuíam direitos de trabalho e/ou direitos previdenciários assegurados por um contrato formal.

Num momento posterior da pesquisa, a técnica de amostragem por "bola de neve" possibilitou encontrar e realizar entrevistas em profundidade com seis empregadas domésticas diaristas com idades entre 29 e 61 anos. A opção pelas entrevistas em profundidade, ainda que tais entrevistas fossem limitadas para captar certos aspectos da atividade em situação, permitiu desvelar aspectos da experiência enquanto "dramas no uso de si" contidos nos modi operandi do cotidiano laboral. Esses aspectos foram observados nas estratégias de administração dos próprios interesses, nos sentidos e nos significados atribuídos, nas maneiras de sentir e pensar a vida e o trabalho do ponto de vista das diaristas que colaboraram com a pesquisa.

As entrevistas também permitiram identificar e descrever os aspectos da trajetória profissional e da história de vida de empregadas domésticas diaristas. Revelaram que uma história social e econômica subterrânea do trabalho doméstico não se explica sem a tessitura das histórias de vida das mulheres e dos usos que fazem de si por si e por outrem nas conjunturas históricas nas quais vivem. Nessa amostra aleatória, apenas uma das entrevistadas já havia trabalhado antes com carteira assinada, e também apenas uma tinha o marido como provedor da família. Já nos primeiros depoimentos das empregadas diaristas, foi possível observar a importância da jornada diária como elemento estruturador da atividade, já que cada casa - espaço privado -, tendo características próprias, exige esforço diferenciado em termos de 
carga e condições de trabalho, organização geral, planejamento e distribuição das tarefas por parte da trabalhadora.

A Classificação Brasileira de Ocupações $(\mathrm{CBO})^{3}$ de 2002 classifica a atividade da empregada doméstica diarista como pertencente à família ocupacional denominada Trabalhadores dos Serviços Domésticos em Geral e estabelece como tarefas dessa ocupação: preparar refeições, lavar, passar, arrumar. O que a diferencia das demais funções na família ocupacional é a realização dessas atividades domésticas num único dia por semana em casas diferentes.

Os depoimentos deixam entrever os riscos à saúde no cotidiano doméstico. Desde riscos físicos associados ao manuseio de produtos químicos até aqueles relacionados ao contato com eletricidade, além de alguns riscos potenciais do trabalho em altura. É evidente que as tarefas são árduas e pesadas, podendo gerar problemas de coluna, varizes etc.

Lavo banheiros, o chão da cozinha, a área, lavo roupa e vasilha. Você não vê nada. Troco toalha de mesa, janela tá sempre limpa para não juntar poeira, mas não reconhece (Lourdes).

Eu limpei a prateleira dela, eu arrumei a casa, aí a poeira subiu e ela cismou que eu não tinha limpado a casa. Eu falei: "Limpei sim!". "Não limpou, Rosi! Isto aqui é poeira de muito tempo!". "Tá bom! Pode deixar que eu vou limpar de novo"[...] para não discutir né? Então a gente nunca tem valor! Para elas, nunca vai tá bom (Rosilene).

Os depoimentos acima revelam o problema recorrente de ausência de reconhecimento por parte dos empregadores, que, nesse caso, estão muito próximos no dia a dia do trabalho. A questão ganha novas proporções à medida que esse trabalho permanece endereçado ao "escuro território do íntimo alheio", no espaço das necessidades íntimas do outro. Sobre esse aspecto, Le Guillant (2006) chamava atenção para a condição servil dessas trabalhadoras como bone a tout faire, condição à qual Lhulier (2005) agregará os efeitos perversos da negação, que promove a invisibilidade.

As entrevistas revelam as estratégias de visibilidade e as resistências para os enfrentamentos adotadas por empregadas domésticas diaristas no cotidiano do trabalho. Além disso, acessam dimensões diversificadas desse uso de si por si, permitindo-nos interrogar também até que ponto é correto considerar esse trabalho precário - classificação cuja justificativa é marcada pela ausência de contrato de trabalho.

[...] penso que é bom trabalhar cada dia em um lugar diferente! [...] e por causa desse negócio de trabalhar no sábado eu optei por ser diarista. Porque aí se eu quiser trabalhar até sexta ou quinta eu programo duas, três faxinas, só. É a melhor coisa, é a melhor escolha poder fazer assim [...] como diarista eu trabalho muito mais. Por exemplo: se eu for na casa da senhora um dia, eu vou ter que fazer o serviço da semana em um dia, né. Mas é bom. Igual, eu trabalho na Virgínia já tem nove anos, a gente nem fala que é patroa e empregada. Parece que a gente é da família uma da outra (Adeires).

O depoimento a seguir, por sua vez, deixa pistas para pensar que a flexibilidade na administração dos dias da semana pode significar, em contrapartida, uma densidade na carga de trabalho a ser gerida num único dia:

"Ralo igual uma cachorra! É só na quinta-feira e é tudo para mim, eu faço tudo. Limpo os vidros, limpo dentro de todos os armários, só eu! Não tem outra pessoa durante a semana não!” (Rosilene).

Observamos também que existem estratégias de inserção no mercado combinadas com o gerenciamento do tempo num circuito, articulando espaços domésticos, o seu e o do outro.

3 Elaborada em 1977, em regime de colaboração técnica entre o Brasil e a Organização das Nações Unidas com base na Classificação Internacional Uniforme de Ocupações (CIUO) de 1968. Cf. portal do Ministério do Trabalho (Brasil). 
Tudo isso tem tornado urgente o processo de regulamentação do emprego doméstico de diarista, mas, ao mesmo tempo, trata-se de um desafio construir normas legais em uma situação de pluriempregador.

A pesquisa vem elucidando que, na ausência de contratualização formal, há uma regulação dos usos (muitas vezes, tácita). A ausência de normas legais de contratação desse uso entre as partes não isenta o trabalho de normas e procedimentos combinados caso a caso. Os sentidos do trabalho desvelam-se nas estratégias de gestão do tempo no cotidiano do trabalho.

É o jeito da casa [...] eu chego vou pra cozinha. Da cozinha eu vou para os quartos e faço tudo pra não incomodar ela. Todo dia, toda terça e quinta, é diferente. Igual, nessa semana, ao invés de ir para as roupas eu fui para os quartos. Mas é ela que manda [...] então só quando é uma coisa diferente que ela manda. Mas eu já sei como é que gosta. Ela só descreve para fazer a comida, o resto não (Ribeiro, 2011, p. 84).

Isso nos permitirá pensar também nas circulações de procedimentos, saberes, valores e modi operandi em situações diferenciadas de trabalho doméstico - cada casa é um caso. Em que pesem toda a fragilidade do vínculo empregatício no setor, a quase ausência de regulamentação na profissão e o contingente de trabalhadores sem carteira assinada, os valores vigentes no exercício do trabalho extrapolam em muito um uso de si precário...

Aí, mesmo que eles não me pagassem, por exemplo, eu ia lá com prazer. Uma pelo tratamento que eles me dão, que eles me tratam muito bem. Nunca me maltrataram. E outra que eu me sinto bem na casa deles, né? Por amor, faço por amor. E até se algum dia eu for trabalhar na casa de algum deles e eles estiverem apertados de dinheiro, não puderem me pagar... "Oh, Dona Lourdes. Eu não vou poder chamar a senhora, não vou poder chamar por um tempo..." por isso não. "Quando você puder, você me paga”... só por prazer de ir lá. Vou mesmo (Lourdes) (Ribeiro, 2011, p. 93).

A ergologia ensina que é impossível vencer toda a exterritorialidade do pesquisador em face do trabalho, atividade que este busca compreender, e esta pesquisa mergulha na atividade de diarista pelo viés dos usos econômicos e socioculturais praticados nesse segmento de mercado. O último depoimento nos introduz nos afetos que circulam na prestação de serviços domésticos, num contexto que é mercantil, mas não estruturado por direitos contratualizados. Assim, remete-nos a planos mais ínfimos no exercício do ofício de diarista, a dimensões latentes, porém estruturantes dos gestos no trabalho cotidiano em território privado - íntimo alheio -, permitindo-nos concluir que sabemos pouco sobre que parte dessas mulheres está no trabalho analisado. É um bom exemplo de como ressonâncias afetivas tensionam o ser nessas situações laborais, convocando outros campos do conhecimento ao debate sobre trabalho. Emerge, então, o desafio do trabalho conceitual, uma vez que não basta somente justapor e encontrar links entre os patrimônios disciplinares. Será preciso retrabalhar os conceitos mobilizados na tentativa de construir conhecimento na busca pela compreensão de tal atividade industriosa.

\section{Problemas em comum}

Entretanto, o essencial dessa empatia que emerge do compartilhamento de atividades não permite a assimilação dos dois patrimônios. Em contrapartida, permite a compreensão de que, trilhando caminhos e tradições diferentes, enfrentando questões teóricas relacionadas à construção de abordagens que captem o homem em seu fazer em meio às relações sociais, a ergologia e a psicossociologia do trabalho têm muito que ensinar uma à outra. A ergologia tem a ensinar o "trabalho do conceito", que possibilitou vislumbrar atividade humana no exercício 
de qualquer ofício contemporâneo, desconstruindo fronteiras interpostas por tradições disciplinares e ortodoxas na abordagem dessa experiência humana que faz todo homem de seu tempo um ser sociocultural. Nesse sentido, a pesquisa apresentada deixa pistas e convida a psicossociologia à reflexão sobre o quanto o conceito de "uso de si" possibilita pensar mais profundamente o conceito de "identidade", caro à psicossociologia do trabalho. À ergologia fica a provocação do quanto ainda devemos aprender na lida com o imaginário social dos trabalhadores, para além dos dramas expressos unicamente em termos de saberes e valores.

Ambas abordagens compartilham da ideia de que a pesquisa se inaugura com os trabalhadores cooperando na construção de conhecimentos de um novo tipo. Ao mesmo tempo, instaura-se uma exigência de humildade para aceitar ser impelido à reflexão com patrimônios epistêmicos diferentes daqueles advindos de sua própria profissionalidade, num diálogo aberto para decifrar o enigma da atividade humana no centro dos acontecimentos dos vários mundos do trabalho e de vida. Essas conjunturas compreendidas com os trabalhadores sempre revelam novos modos de fazer e de viver, desafiando nosso imaginário à transformação social e histórica.

\section{Referências}

Amado, G. \& Enriquez, E. (2011). Psicodinâmica do trabalho e psicossociologia. In P. F. Bendassolli \& L. A. Soboll (Orgs.). Clínicas do trabalho. São Paulo: Atlas.

Amado, G. (1994). La ressonance psychosociale au coeur de la vie e de la mort. Revue Internationale de Psychosociologie, 1, 87-94.

Carreteiro, T. C. O. \& Barros, V. A. (2011). Clínicas do trabalho: contribuições da psicossociologia no Brasil. In P. F. Bendassolli \& L. A. Soboll (Orgs.), Clínicas do trabalho. São Paulo: Atlas.

Chapoulie, J. (1984). Everett C. Hughes et le développement du travail de terrain en Sociologie. Revue française de Sociologie, 25 (4), 582-608.

Hughes, E. C. (2010). Les honnêtes gens et le sale boulot. Revue Travaille, 24, (2), 21-34.

Le Guillant, L. (2006). Incidências psicopatológicas da condição de "empregada domestica". In M. E. A. Lima (Org.), Escritos de Louis Le Guillant: da ergoterapia a psicopatologia do trabalho. Petrópolis, RJ: Vozes.

Lhuilier, D. (2005). Le "sale boulot". Revue Travailler, 14, 73-98.

Mariuzzo, P. (2006). Socióloga discute o desemprego e a questão de gênero no mundo do trabalho. Revista Inovação, $2(5), 1-4$.

Mata Machado, M. N. (2010). Intervenção psicossociologia, método clínico de pesquisa e de construção teórica. Revista Pesquisas e Práticas Psicossociais, 5 (2), 175-181.

Oddone, I., Re, A. \& Briante, G. (1981). Redécouvrir l'expérience ouvrière. Paris: Éditions Sociales.

Ribeiro, C. R. B. (2011). Usos de si e informalidade no trabalho da empregada diarista. Belo Horizonte: PPGEFaE/UFMG (Relatório de qualificação de doutorado).

Schwartz, Y. (Org.) (1987). Reconnaissances du travail: pour une approche ergologique. Paris: PUF.

Schwartz, Y. (1996) Ergonomie, philosophie et exterritorialité. In F. Daniellou (Org.), L'ergonomie en quête de ses principes: débats épistémologiques. Toulouse: Octarès.

Schwartz, Y. (2000). Le paradigme ergologique ou un métier de philosophe. Toulouse: Octarès.

\section{Endereço para correspondência}

daisy-cunha@uol.com.br 